\title{
Dominican Republic and Mexico \\ Promote Condom Use by Emphasizing Personal Benefits
}

Condom Use OR Summary 50

\section{Studies in the Dominican Republic and Mexico showed that regular condom users obtained personal benefits from condom use, including a sense of security. Condom promotion initiatives should emphasize the positive aspects of condom use and make condoms available through alternative venues.}

\section{Background}

Along with strategies about abstinence and being faithful, (ABC), consistent and correct use of the male condom is a critical measure for preventing STI-related morbidity and mortality. Yet condom use remains low worldwide. The majority of studies to date have identified various attitudes and beliefs that contribute to the failure of condom use or effectiveness. Researchers have made only limited progress on identifying positive factors that facilitate regular condom use.

From 2001 to 2003 the Population Council, the Interagency Gender Working Group, and the Moriah Fund supported studies in Santo Domingo, Dominican Republic and Ciudad Juarez, Mexico to explore the behavior of individuals who use condoms successfully. Findings on factors that facilitate or impede successful use could be used to develop more effective condom promotion strategies in family planning and STI prevention programs.

The projects used qualitative data from successful condom users within three categories: male and female factory workers; male and female high school and university students; and female sex workers and their male clients. Researchers screened successful condom users through a 75-point scale that assessed the frequency and effectiveness of condom use as well as positive and negative experiences with condoms. Those who scored 38 points or higher on the scale were invited to participate in focus group discussions (three to five per category and eight to 15 participants per group). Researchers analyzed data from survey responses and transcriptions from focus group discussions to identify the characteristics and attitudes of condom users.

\section{Findings}

- Focus group participants defined successful condom use in terms of personal benefits, such as avoiding pregnancy, preventing STIs, feeling secure, or improving hygiene. This contrasts with previous studies that have defined successful condom use in terms of frequency and consistency of use.

- The major reasons for using condoms were preventing pregnancy (the main reason for women) and protecting against STIs (the main reason for men). A third major reason was that the protection of condoms gave a sense of security and peace of mind. Participants liked the convenience and easy availability of condoms, and some women said that they used condoms because they were dissatisfied with other contraceptive methods. 
- The majority of participants said that condom did not diminish sexual satisfaction but instead enhanced their sexual enjoyment. They reported that the security of condom use made them feel safer and more relaxed.

- Condom use was more likely with casual or irregular partners. Almost three-fourths of the sex workers interviewed in the Dominican Republic reported always using condoms with clients; use with non-clients was much lower. Over half of students and factory workers in both countries used condoms with casual partners. However, a significant proportion said that even with casual partners, they rarely or never used condoms (see Figure).

- About a third of students and factory workers reported always using condoms even with stable partners. In focus group discussions, participants cited several reasons for this, including mistrust of regular partners, desire for protection from pregnancy or STIs, and the convenience and hygiene of condom use.

- Focus group participants disclosed various strategies to persuade partners to use condoms, including bringing a supply of condoms, eroticizing condom use, and refusing sex without a condom. Members of all three groups mentioned talking about condoms to encourage use. However, some participants were reluctant to bring up condoms with regular partners because it would imply infidelity.

- Buying condoms in public venues, such as pharmacies, remains stigmatized and embarrassing, even for experienced users. They urged that condom dispensers be available at alternative outlets, such as discos, workplaces, and universities.

\section{Frequency of condom use by students or factory workers during a six-month period, by type of partner}

\begin{tabular}{|l|c|c|c|}
\hline & $\begin{array}{c}\text { Always } \\
(\%)\end{array}$ & $\begin{array}{c}\text { Often } \\
(\%)\end{array}$ & $\begin{array}{c}\text { Seldom } \\
\text { or never } \\
(\%)\end{array}$ \\
\hline \multicolumn{3}{|c|}{ Students } \\
\hline $\begin{array}{l}\text { Stable partner } \\
(\mathrm{n}=180)\end{array}$ & 32 & 36 & 32 \\
\hline $\begin{array}{l}\text { Casual partner } \\
(\mathrm{n}=104)\end{array}$ & 59 & 27 & 13 \\
\hline \multicolumn{3}{|c|}{ Factory workers } \\
\hline $\begin{array}{l}\text { Stable partner } \\
(\mathrm{n}=129)\end{array}$ & 31 & 21 & 47 \\
\hline $\begin{array}{l}\text { Casual partner } \\
(\mathrm{n}=61)\end{array}$ & 66 & 11 & 25 \\
\hline
\end{tabular}

Source: Survey answers from students or factory workers who reported having had a sexual partner during the past six months

\section{Utilization}

- Local organizations in both countries have reviewed their condom promotion strategies and materials. Revised materials will be tested in both countries.

\section{Policy Implications}

- Condom education campaigns should increase their focus on the benefits of condom use. Suggestions include promoting condoms for protection of families, for increased security and pleasure, and as a show of love and respect for the partner. Condom users should be depicted as responsible role models.

\footnotetext{
- Programs are needed to encourage discussion of responsible and safe sexuality by many stakeholders including parents, adolescents, businesses, and physicians. Messages should also touch on the link between self-esteem and condom use, such as "if you love yourself, you will use a condom."
}

Sources: García, Sandra G. and Lisa Goldman. 2004. "Understanding Successful Condom Use in the Dominican Republic," FRONTIERS Final Report. Washington, DC: Population Council, and García, Sandra G. and Lisa Goldman. 2003. "Understanding Successful Condom Use in Northern Mexico." Final Narrative Report. New York: Population Council. Available on our website at www.popcouncil.org/ frontiers/frontiersfinalrpts.html or by e-mail:frontiers@pcdc.org.

These projects were conducted with support from the U.S. AGENCY FOR INTERNATIONAL DEVELOPMENT under Cooperative Agreement Number HRN-A-00-98-00012-00 and from the Moriah Fund. 